\title{
Acute Gastric Ischemia Following Severe Hypotension During Epidural Anesthesia
}

\section{Nikolaos Giorgakis*, Sotirios Anastasiadis, Jannis Kountouras and Panagiotis Katsinelos}

Gastroenterology Section, Second Department of Internal Medicine, Hippokration Hospital, Aristotle University, Thessaloniki, Greece

*Corresponding Author: Nikolaos Giorgakis, Gastroenterologist, PhD Candidate, Gastroenterology Section, Second Department of Internal Medicine, Hippokration Hospital, Aristotle University, Thessaloniki, Greece.

DOI: $10.31080 /$ ASGIS.2020.03.0120
Received: January 23, 2020

Published: February 14, 2020

(C) All rights are reserved by Nikolaos

Giorgakis., et al.

\section{Abstract}

A case of acute gastric ischemia caused by severe hypotension that despite the rich vascular supply of stomach, ultimately ended to death.

Keywords: Gastric; Ischemia; Hypotension; Epidural; Anesthesia

\section{Introduction}

The following case report provides evidence that in severe systemic hypotension even in the event of proper resuscitation, not only liver but gastric wall could as well suffer significant ischemic lesions, that under certain circumstances could end in a significantly adverse effect.

\section{Case}

A 47 years old woman was admitted to the Orthopedics Department because of femoral bone fracture. Before starting reduction surgery of the fracture, during epidural anesthesia the patient developed severe systemic hypotension accompanied by idioventricular rhythm. She was administered crystalloid and colloid solutions and treated with intravenous dopamine and noradrenaline in the intensive care unit. Laboratory data of next day were compatible with 'shock liver' (significantly high levels of transaminases and lactic dehydrogenase). Bloody content was aspirated from nasogastric tube on day 3. Endoscopic examination demonstrated large gangrenous areas at the anterior and posterior wall of stomach (Figure 1) with a clear demarcation between healthy and ischemic gastric mucosa. Patient succumbed to septic complications 10 days later.

\section{Discussion and Conclusion}

The most vulnerable abdominal organs during severe hypotension are usually the liver, manifesting as ischemic liver disease, otherwise known as 'shock liver', and ischemic bowel disease [1]. Rich collateral blood flow and extensive submucosal vascular network protect stomach from necrosis even after ligation of all major vessels [1]. The causes of gastric ischemia can be vascular, mechanical, toxic, inflammatory, infectious, autoimmune or idiopathic [1-4].

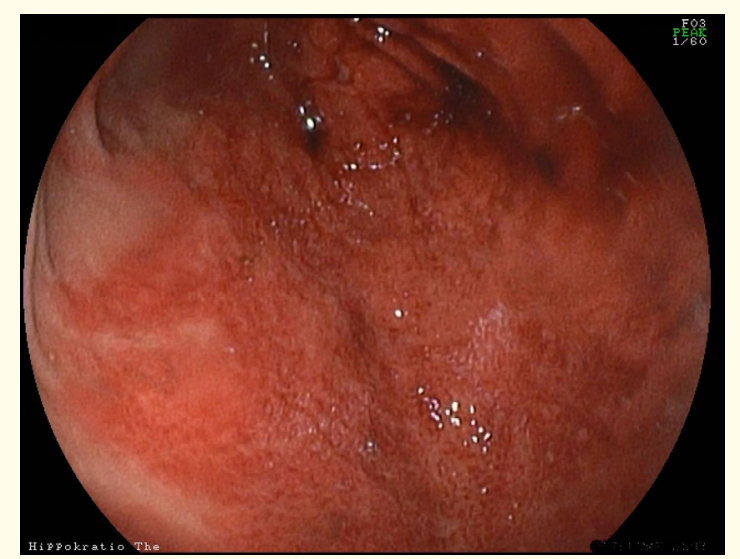

Figure 1: Endoscopic view of gangrenous areas covering a large part of stomach with clear demarcation of ischemic and uninvolved gastric mucosa.

Acute gastric ischemia, poorly known by physicians, is a very rare and often lethal entity. Regarding our patient, we believe that ischemic gastritis was a unusual consequence of visceral hypoperfusion secondary to severe systemic hypotension related to epidural anesthesia, ultimately leading to death.

\section{Conflict of Interest}

None.

\section{Bibliography}

1. Richieri JP., et al. "Acute necrotizing ischemic gastritis: clinical, endoscopic and histopathologic aspects". Gastrointestinal Endoscopy 48.2 (1998): 210-212. 
2. Edlich RF., et al. "Gastric blood flow. Its distribution during gastric distention". American Journal of Surgery 120.1 (1970): 35-37.

3. Schultz MJ., et al. "Acute phlegmonous gastritis". Gastrointestinal Endoscopy 44.1 (1996): 80-83.

4. Rieger A., et al. "Total gastric necrosis subsequent to acute pancreatitis". Pancreas 41.2 (2012): 325-327.

\section{Assets from publication with us}

- Prompt Acknowledgement after receiving the article

- Thorough Double blinded peer review

- Rapid Publication

- Issue of Publication Certificate

- High visibility of your Published work

Website: www.actascientific.com

Submit Article: www.actascientific.com/submission.php

Email us: editor@actascientific.com

Contact us: +919182824667 